\title{
Research Universities in the Next Decade
}

\begin{abstract}
The major research university, a uniquely American institution, has emerged from a period of unrivaled expansion and success to face an array of critical problems. These problems include altered attitudes regarding the value of social institutions, rapid inflation, government regulation, and mixed views of scientific and technological advancement. This is coupled with the uncertainties surrounding the relationship between the federal government and higher education. In order to face this future effectively, research universities must seek to retain a necessary level of federal support, to secure new partners and alliances to augment this support, and to ensure that primary agenda-setting responsibility for their teaching and research programs continues to reside with their faculties, administrators, and trustees.
\end{abstract}

$\mathrm{F}$ OR THE LAST eighteen months or so, I have had the opportunity to look at some matters affecting the condition of the nation's research universities. (Parenthetically, and before I am asked, let me simply stipulate that, for our purposes, a research university is any university with a research library. I think that throws the ball into your court.) This effort has gone forward under the auspices of the Association of American Universities and with the guidance of an advisory group consisting of university presidents, foundation executives, and businesspersons. Our purpose was to look at the political, economic, and social circumstances that affect those institutions, to identify their major needs, and to suggest an agenda for action to meet those needs. The agenda was directed at the institutions themselves, at government, and at the private sector. We gave particular attention to the topics of research libraries, research instrumentation, graduate education and research training, international studies, and business-higher education collaboration.

We did not set out in this work to predict the future or even to speculate about the way this important group of institutions is likely to

Robert M. Rosenzweig is vice-president for public affairs, Stanford University, Stanford, California. develop in the next decade. Our aim was somewhat more modest. It was to get a better fix on where we now stand and to understand better the dynamics of some important relationships involving the universities and their patrons. With that knowledge we may be able to shape our own future more effectively.

It is not that I am opposed to efforts to predict the future. Those efforts are frequently entertaining, and occasionally one or another prediction turns out to be right. On the whole, though, we are of necessity so rooted in where we have been and where we are that it is very hard to know where we and events will take us. I do have some very broad impressions about the future that I will share with you a bit later, but just in case you think that I am urging an unduly humble view of the matter, we can review the recent record.

In 1960, the main concerns of leaders in higher education centered on the problems of growth. The 1950s had been marked by a convulsive burst of expansion produced by the need to accommodate the veterans of World War II and the war in Korea. Ahead lay the children of the postwar baby boom and the desire of larger fractions of each year's high school graduating class to attend college.

The issues of the day concerned the best ways to stimulate growth in order to accom- 
modate the new demand. The National Defense Education Act of 1958 provided fellowships for doctoral programs willing to expand their size in order to educate larger numbers of college teachers. NSF and NIH fellowship programs grew in parallel. Agitation had begun for federal programs to aid new academic facilities in accommodating the growing student numbers. The great systems of public higher education were ready for their periods of greatest growth, and federal support for scientific research was increasing each year.

In America, growth has been the foundation of optimism, and in that sense as well as others, 1960 was an optimistic year. Indeed it was the last decade-opening year in the experience of those now active in higher education to be marked by genuine optimism about the future. Let it be said, then, that only the gift of prevision would have enabled one to see all that lay ahead in the 1960s. Not only did the 1960 s witness the largely successful culmination of an unprecedented growth in the system, but it also brought some of the unhappier fruits of that expansion and more.

No one can be faulted for failing to foresee the war in Vietnam, the draft, the civil rights movement followed by violent racial unrest, and the assassination of three of the nation's leading public figures. Their effects, therefore, came with the shock born of surprise. Less understandable, perhaps, was the failure to see early enough that growth, no matter how well managed, produces dislocations. Eventually it became evident that many undergraduate students were less than enthusiastic about the growth of graduate programs and the ready availability of research funds, as both enabled their teachers to withdraw from undergraduate teaching, and that the very increases in enrollment that marked the decade served to sharpen the pain and anger of minorities who were still largely on the outside looking in.

The year 1970, therefore, was anything but optimistic. Indeed, it was hard to find on the agenda issues of education policy as that term is ordinarily understood. Instead, America's educational leadership was preoccupied with issues of disruption, violence, retribution from political leaders who had no answers but keen noses for a useful political issue and other matters that were far re- moved from the experience, training, or inclinations of most.

What is most striking about the 1970s is just how transitory those preoccupations turned out to be. By 1973 the war was over, the draft was no longer a threat, the practice of politics had reverted to its more normal rhythms, and the campuses were deeply troubled about issues whose early warnings had been overridden by the convulsions of the preceding years. The government, both in anger at the antiwar movement and in response to competition from new priorities, turned down the tap on research spending. Graduate fellowship programs were sharply reduced, and funds for academic facilities virtually disappeared. In addition, a whole new set of issues arose, generated by a wave of regulatory activity. Some of the activity grew directly out of demands for greater accountability in the use of federal money, but much of it came to universities simply because they were large organizations doing business in a political climate that encouraged the discovery of new abuses needing to be controlled.

One can find both good news and bad in this brief sketch. The good news is that the record of dealing with the issues that were known to be issues has been excellent. The bad news, alas, is that it seems almost impossible to avoid unpleasant surprises. From the former we may take hope; from the latter we should learn humility.

With that as background, I am able to say that my own view of the future of higher education, and especially that part of it that is encompassed by the research universities, lies somewhere north of Cassandra and south of Polyanna. I believe that things are not as bad as we sometimes think they are, and that with the application of intelligence and energy it should be possible to keep them from getting much worse. I shall now back up and approach that conclusion in a more orderly way. Along the way I shall make some observations about the immediate future, as represented by the policies of the Reagan administration, and also a few suggestions about what is required as a foundation for policies.

America can boast of institutions with distinguished teaching as their main activity and others that devote their full efforts to high-quality research, but what sets the American scene apart from all others is the 


\section{4 / College \& Research Libraries • March 1982}

existence of a group of institutions whose commitment is both to teaching and to research and to the belief that the interaction of the two brings added value to both.

Is the belief more than that? Is it more than simply a conviction born of convenience and of the ease of justifying existing structures? Evidence for the value of particular forms of social organization is notoriously difficult to find. In the real world genuine comparisons - the kind that support confident generalizations - rarely exist. Still, most informed observers throughout the world would agree that the American research university must be judged a success by virtually any imaginable standard of measurement. It has been the home to research and scholarship that, across all fields and in the aggregate, is unexcelled anywhere in the world; it has trained research scientists and scholars of the highest quality, as well as doctors, lawyers, and managers of great sophistication, and it has, notwithstanding a commitment to basic research, retained a connection to the worlds of commerce and affairs that enriches commercial and public life.

The existence of these universities represents a remarkable achievement. A form of social organization barely known elsewhere in the world has so clearly demonstrated its value in America that the wisdom of sustaining it is almost beyond serious debate. While it may now seem so, it is important to recall that this result was not inevitable. Much of the scientific work that proved the practical value of science during the Second World War was done by university scientists, but not in truly academic settings. There was no necessary reason to conclude from that experience that research and teaching would both be better if they were done together. The tradition of the research university was not widespread or well entrenched in this country. On the contrary, the main existing examples of how to conduct basic research were those of Great Britain, the Continent, and the war, and to emulate them could well have led to a different conclusion. That those examples did not become America's model is a significant achievement of both education and politics.

If it was a development born of wartime experience, it was confirmed by equally powerful impulses in the years that followed. The competition of the cold war maintained the high public interest in science and technology as the foundation of military preparedness, and it also provided the momentum for initiatives as diverse as the space program and the stimulation of programs of research and teaching in foreign languages and cultures. The effect was to confirm the value of the university to important national purposes.

In addition to war and cold war, other forces moved in the same direction. The arrival of at least relative peace and unquestioned prosperity helped to move the national concern for health to a high place on the list of social and political priorities. Early on, the cure of disease was seen to depend on knowledge of basic biological processes, and as a consequence of rapidly growing popularity, the National Institutes of Health became the instrument for the expansion of healthrelated research and training in university laboratories. Similarly, the extension of social insurance programs to health care through Medicare and Medicaid greatly stimulated the need for physicians and other health care personnel and placed the government in the position of major purchaser of the health care services that many university teaching hospitals used as the basis of their training. Thus, from basic research on the structure of life, to the application of research in therapy, to the training of researchers and practitioners, to the delivery of medical service, the university became the instrument of choice by means of an unbreakable mutually dependent relationship with the government.

Recognizing the development and confirmation of the research university as an achievement - a successful product of social choice, educational initiative, and political skill - may help lend perspective to a number of collateral questions. Such issues as the pressures for wider geographical distribution of research funds, the role of peer review in decisions about funding, and the baneful effects of effort reporting requirements, for example, are important, and if they are dealt with unintelligently they can have a cumulatively harmful effect on the quality of research and teaching. But they arise in the context of a broad intellectual and political consensus over the value of the institutions they affect.

But the substance of public policy flows 
from a climate of events and attitudes that establishes what is necessary and determines what is possible. Therefore, some important aspects of the American climate need to be accounted for if sensible policies for the 1980s are to emerge. The main facts of contemporary American life from the perspective of research universities are the corrosive effects of a widespread indifference-even hostility - to the well-being of important social institutions; the equally corrosive effects of rapid and sustained inflation; the active role of government in regulating economic and social activity; and the growing importance of and ambivalence to science and technology. Even that list is by no means complete, but it suggests a world of sufficient complexity to challenge the most intrepid among us.

These have not been easy times for the central institutions of American society. The worst of the late 1960s and early 1970 s is perhaps behind us, but the legacy of Vietnam and Watergate remains. Instead of the virulent animosity of that period, one senses today at best a widespread skepticism about the capacity of our social institutions, governmental and private alike, to do what is required of them.

There may be some comfort to be taken from the consistent showing in the polls that the public at large retains an ability to discriminate among the objects of its disaffection. In general, institutions of government, business, and the organized professionswhat might generally be called the institutions of power and privilege-rank low in public esteem. In contrast, public regard for science, universities, and religious institutions has rebounded from its lowest point.

Unhappily, however, the leaders of opinion seem to be less discriminating. The media delight in exposing the warts of government, education, the judiciary, and anyone else in their line of vision. Government too often acts as if its preoccupations of the moment override all other considerations, including the ability of other institutions to perform their roles. Single-interest groups, notoriously unconcerned about anything outside the narrow scope of their particular visions, attack government, business, universities, and the media with ready and equal abandon.

None of this, perhaps, should be surpris- ing. For almost two decades we have been a nation buffeted by shocks and bewildered by a confusion of seemingly intractable problems. We are also a people who like solutions and who have a low tolerance for ambiguity, complexity, and uncertainty. Faced with pressing problems, we press for quick answers. We applaud those who offer them and scorn those who can tell us only how complicated it all is. It is a climate tailor-made for anti-institutionalism, for institutions are nothing if they are not conservative: it is in their very nature to exalt process over substance, to insist on the importance of continuity and precedent, and to avoid actions that may threaten their survival.

However, these are extremely valuable qualities; they are, in fact, part of the glue that holds stable societies together. It happens, though, that they are out of joint with this particular time. The core of the problem is that the most valuable and most responsible of our institutions are conveying the least welcome message, namely that there are no easy solutions, that we must learn to live with our afflictions, and that it is precisely in such circumstances that stability and continuity are of greatest value.

The best universities in the land, those with the most intellectually active faculties and the ablest students, are in a particularly difficult bind. They are at one and the same time the most conservative and the most radical of social institutions. They retain their eminence by the most rigorous insistence on high standards of performance and evaluation and by a sometimes painful adherence to the procedures of judgment and of inquiry that have been tested in centuries of experience. They are, thus, correctly perceived as the source of much of the change that has made life so difficult. It may be paradoxical, but it is nevertheless a key truth that by insisting on conservative processes, the best universities guarantee the most radical results.

The examples are legion and they involve every aspect of life. In the sciences, dramatically altered conceptions of the nature of matter in the universe and of the fundamental biological and chemical structures of life-conceptions that demand the sacrifice of old certainties as the price of new understanding-have stemmed primarily from work done by university-based scientists 
in university laboratories. In the social sciences, work done in a few major universities showed the power of scientific public opinion sampling as a tool for explaining political behavior, a development with profound consequences for the way in which politics is now conducted in this country. In the professions, much of the change in medical practice of the last three decades - improved therapies, new technologies, increasing specialization - can be traced to the work of university-based biomedical sciences. And law school faculty members have been instrumental in generating the justification for new law in such key areas as civil rights, civil liberties, capital punishment, consumer protection, environmental protection, political reform, and a host of others.

All of these are signs of vitality, evidence that universities are in fact the setting for work of profound importance. But it also needs to be said that intellectual labor that has real consequences for the way society does its business is certain to generate controversy. Indeed, the more rapid the rate of change, the more intense will be the anxiety it evokes about the institutions that appear to be responsible for it.

A second important element of the social climate is not new, but the full recognition of its dimensions and effects is new to universities. It is the extent to which the conduct of institutions has become subject to the regulatory power of government. The United States is by no means alone in this regard. Indeed, if anything, most other democratic nations of the West started earlier and have gone further in their efforts to use government to guide economic activity, cushion the harsher effects of economic competition, redistribute income, and promote the public's health and safety.

Initially, the power of government was used in this country to stimulate competition by preventing monopoly and to protect against the abuse of power by sectors of industry - transportation and utilities, for example-whose scale was inevitably large and whose power was therefore great. Add to those a relatively small number of governmental activities aimed at protecting public health, and it is not hard to see why universities were relatively untouched by regulatory activities.
By the 1960s the end of innocence was in sight, and by the 1970 s it was truly gone. Three developments coincided to alter circumstances dramatically and irrevocably. The first was simply that universities became too large, important, and visible to ignore any longer. The maintenance worker in the university could not be denied the protection of the government for his right to join a union on the grounds that universities were not really engaged in commerce or were somehow too small or idiosyncratic to be reached by the same law that protected the rights of maintenance workers across the street.

Second, the very nature of regulation changed in ways that made universities central rather than peripheral to the regulatory purpose. When, for example, government assumed the duty to redress the effects of two centuries of racial discrimination, it was inconceivable that schools at any level could be exempt. Similarly, the dramatic shift of public focus from the regulation of certain kinds of economic activity to the use of regulatory powers in protecting against risks and hazards of many different kinds, brought universities into the regulatory arena more fully than before. Environmental protection, consumer protection, protection of the subjects of research, protection against toxic wastesall of those at a minimum include and in some cases focus on universities as sources of hazard from which the public arguably needs protection.

The perception, therefore, that government reaches more broadly and deeply into university activities than ever before is quite accurate. However, the belief of some that universities are uniquely put upon in this respect would be largely incorrect were it not for the third and most recent of the regulatory impulses, the one that has come under the heading of "accountability."

The principle of accountability - in simplest terms, the requirement that recipients of public money be able to demonstrate that they used the money for the purposes for which it was given - is hardly controversial. Controversy, and it is bitter indeed, arises over the insistence by government on forms of documentation that are widely believed in academic circles to be unreasonable, intrusive, burdensome, and useless, to use only terms that imply no malevolent motives. 
At present, the controversy over accountability centers on the requirements for the documentation of faculty effort to support government payments for the direct and indirect costs of research. Many faculty bitterly resent having to account for the division of their time into such categories as research, teaching, and administration, activities that often take place simultaneously and are therefore indistinguishable from one another. The accumulation of data that anger and demean the giver and are of no practical use to the receiver, is at best a dubious activity. It is also a wholly unnecessary controversy. The careful and balanced report of the National Commission on Research proposes several ways to assure accountability by institutions without the burdensome and contentious requirements that now exist.

It is tempting, because it is easy, to think of regulation as the product of careless legislators or overreaching bureaucrats; or alternatively as a concoction of liberals on social issues and conservatives on financial issues. There is perhaps some truth to each of those, but they are all wide of the mark. The tide of deregulation in recent years has helped to roll back certain restraints on airlines and truckers, and others may follow. It has also helped to call attention to excesses in other areas. It is unlikely, however, that today's reaction will reverse (1) the conditions of modern life that lead citizens to call on government for protection from the hazards that this life produces, or (2) the economic conditions that lead to tight controls on the use of public funds or to the drive to remedy the legacy of racial, ethnic, and sexual discrimination.

The persistence of conditions that lead government to control the conduct of other institutions whose activities affect the public may seem to present a discouraging prospect. But it also suggests a strategy - a strategy that assumes that issues of government regulation will be with us for the foreseeable future, that they are in fact a continuing part of the social climate, and that no single conflict can be treated as if it will be the last one, if only it can be won. The responsibility of political leaders is to define areas in which protection of the public's interest can be achieved only by regulatory activity; the responsibility of those in universities is to define the areas in which the intrusion of government so distorts institutional purposes and processes that the regulatory end being sought must defer to the damage that regulation will cause.

The Reagan administration came to office with an ideological commitment to reverse the regulatory impulse. One of its early actions was the establishment of a task force chaired by the vice-president to move in that direction. That group will not produce miracles. It does, however, provide a new arena for the kind of thoughtful and persistent efforts that will be needed to attain agreement on the proper limits of regulatory activity.

Persistence, intelligence, and restraint are such frequently advised strategies that they may seem to be no strategies at all. In protracted struggles with high stakes, however, they constitute the only workable strategies available.

Finally, in this assessment of the policymaking climate, it is necessary to look at the role of government; not government as regulator, but government as the main stimulus of the postwar development of the research university and as the continuing largest single patron of research and research training.

In approaching this very large and important topic it is useful to begin by saying that it is now a part of the American policy consensus that the federal government bears an important share of the responsibility for sustaining the vitality of the research university. To put the matter in this way purposely begs the very important questions of the size of the share and the best means for supplying it. However, those are the stuff of policy, and policy rests on the fundamental points of consensus: that there exists a federal responsibility and that it is shared with others.

Further confirmation of that consensus can be found in the first Reagan budget. From the point of view of higher education, that budget presented many problems. Even from the narrower perspective of the research universities, the budget displayed an alarming animus toward the social sciences and a disappointing narrowness of view with respect to such matters as graduate training and research instrumentation. But the fact remains that in the midst of the largest proposed budget reductions in our history, universitybased research support in the aggregate was uncut in real dollars. It was extraordinary testimony to the durability of the mutual de- 
pendency that has arisen over the years.

It is merely melodrama to argue, as some do, that the major American universities have become in some sense "federal universities," wards and helpless dependents of the government, but it is surely true that the enormous growth of government programs has produced large and lasting changes in the shape and style of institutional life.

The sheer magnitude of the enterprise has had its own effects on institutions, but the dominance of a single patron was itself a fact of significance. That single patron was so openhanded, so generally enlightened, and so uncritical for so long a time that misconceptions about its nature and purposes grew, and unrealistic expectations about its intentions became embedded in institutional planning. If the relationship between the federal government and research universities has soured in recent years, at least part of the explanation can be found in those misconceptions and false expectations. To put the matter bluntly, too many scientists and university officers came to believe that the governmentuniversity relationship was somehow exempt from ordinary rules of democratic politics. To say that is not to be especially critical. It is simply another way of observing that few of us are so ruthlessly analytical as to question the reasons for the good fortune that comes our way. It is much more common to conclude simply that it is ours because we deserve it.

The attitude was virtually universal among scientists and nearly so among university administrators. The record shows few warnings that business with governmentespecially a democratic government - is inevitably political; that the relationship between government and the interests that make up society is based, to a significant degree, on calculations of mutual advantage; and that government is an unstable ally precisely because those calculations are subject to rapid change as the public perception of the priority due to particular social problems shifts. A fair reading of the record will show that research and higher education had an unusually long run of governmental favor and that, in fact, they have not really fallen from favor so much as they have suffered from increased competition for it.

To be precise, funding for academic re- search and development grew (in constant 1972 dollars) at an annual rate of 12 percent from 1953 to $1960 ; 14$ percent from 1960 to 1968; zero percent from 1968 to 1974 ; and 4 percent from 1974 to 1978 . Fifteen years of such high rates of growth is an extraordinary record of abundance, a record that made the drop to zero both shocking and unconscionable. The small real increases of recent years rank academic research and development as among the more favored of the discretionary objects of governmental patronage.

The dominant view in university and scientific circles tends to be rather different. That view is best expressed in the image of partnership, perhaps the single metaphor most commonly used to describe the relationship of government to research and research training.

It is an attractive image, for genuine partners to an enterprise have common interests, work closely and cooperatively together, and are mutually supportive. But it is also a misleading image, for true partners - in the business sense, for example - have a shared commitment to a common goal, a shared responsibility based on mutual interest for the well-being of the enterprise, and each partner will suffer in precisely defined measure in the case of default of obligation. None of those is true, absent literary license, for the government-university relationship. In the nature of things, government cannot be a true partner. Its commitments are always contingent, and frequently no more than annual, and they are subject to short- or longrun changes depending on circumstances that have nothing to do with the terms or conditions of the "partnership." In the coldest and clearest view of the matter, research universities have no more claim to "partnership" with the government than do farmers, merchant shippers, highway builders, or any other group that has established a claim on government patronage. The government can be, and often is, at one and the same time a patron, adversary, buyer, and regulator. What it cannot be, in any sense that can be relied upon, is a partner.

Much of the bitterness over the deterioration of relations between government and research universities that marks the present climate can be traced to a conviction among the latter of betrayal, deriving from the belief 
that this relationship is somehow different from all others. In some of its details that was undoubtedly true, but in its fundamentals it could not be. Sound future policies and the prospects for good relations in the future depend on a clear-eyed formulation of what agencies in the society are responsible and in what measure, for ensuring that these invaluable and irreplaceable institutions are able to perform at top effectiveness over a long period of time.

The main elements of such a formulation are clear enough. It must surely include frank recognition that the maintenance of a vital research enterprise in the country is unthinkable without the active involvement of the government. It must also include recognition of the inherent instability of that involvement, both as to its total at any moment and as to the components of the total, and therefore it must seek ways to limit dependency on government funding. It must include a reaching out for new patrons and new alliances. The United States still retains a vital private sector that derives important benefits from the work of research universities. New ways need to be devised to make business, in particular, a more active participant in the activities of research and training. Finally, such a formulation must be explicit that the primary responsibility for maintaining the vitality of the research university rests with the faculties, administrators, and trustees who hold them in stewardship during their tenures in office. This is more than mere rhetoric. Dependency can sap responsibility, and in this case the ordinary dangers of excessive dependency on a major patron are exacerbated by the extent to which this patron - the public through its government - has come habitually to depend on the research university to solve its problems - defense, space exploration, disease, health care, and now industrial productivity and innovation. The urgency that such needs bespeak, and the pressures they generate for fast results, can be so overpowering as to distort institutional purposes, and compromise high standards of quality. To avoid those results will require strong institutional agendas combined with strong instruments for defining collective institutional interests. Those responsibilities cannot be given to others except at great cost.

None of this necessarily foreshadows disaster. The American research university has become a remarkably productive institution, host to a large number of creative people whose work pushes back the boundaries of ignorance and helps distribute the benefits of knowledge. The task of policy today and tomorrow is to produce the conditions that will sustain them in their work. 